\title{
Concentration of cytokines in patients with osteoarthritis of the knee and fibromyalgia
}

This article was published in the following Dove Press journal:

Clinical Interventions in Aging

I 2 June 2014

Number of times this article has been viewed

\author{
Marta Imamura' \\ Rosa Alves Targino' \\ Wu Tu Hsing 2,3 \\ Satiko Imamura' \\ Raymundo Soares Azevedo 3 \\ Lucy Santos Villas Boas ${ }^{4}$ \\ Tania Regina Tozetto- \\ Mendoza ${ }^{5}$ \\ Fábio Marcon Alfieri ${ }^{1,6}$ \\ Thais Raquel Filippo' \\ Linamara Rizzo Battistella ${ }^{1,7}$ \\ 'Clinical Research Center, \\ Institute of Physical Medicine and \\ Rehabilitation, University of São Paulo \\ Medical School, São Paulo, ${ }^{2}$ Division \\ of Physical Medicine, Center for \\ Acupuncture, Institute of Orthopedics \\ and Traumatology, University of \\ São Paulo, São Paulo, ${ }^{3}$ Department \\ of Pathology, University of São Paulo, \\ São Paulo, ${ }^{4}$ Laboratory of Medical \\ Investigation LIM-52-HCFMUSP, \\ Institute of Tropical Medicine, \\ University of São Paulo, São Paulo, \\ ${ }^{5}$ Tropical Laboratory of Hematology/ \\ Medical Research Laboratory-LIM 52, \\ Institute of Tropical Medicine, \\ University of São Paulo, São Paulo, \\ ${ }^{6}$ Program of Master in Health \\ Promotion, São Paulo Adventist \\ University Center, São Paulo, \\ ${ }^{7}$ Department of Legal Medicine, \\ Medical Ethics, Social and Labor \\ Medicine - Medicine School, \\ University of São Paulo, São Paulo, \\ Brazil
}

Correspondence: Fábio Marcon Alfieri

Clinical Research Center, Institute

of Physical Medicine and Rehabilitation,

University of São Paulo Medical School,

Rua Jandiatuba 580, 057I6-I50

São Paulo, Brazil

Tel +55 II 39058616

Email fabioalfieri@usp.br
Introduction: Fibromyalgia and osteoarthritis may present a relationship with the concentration of cytokines. The aim of this study was to compare the serum concentrations of IL-12p70, tumor necrosis factor, IL-10, IL-6, IL-1 $\beta$, and IL-8 in patients with knee osteoarthritis and fibromyalgia.

Materials and methods: The study included 53 women ( $71.2 \pm 7.6$ years old) diagnosed with knee osteoarthritis with moderate-to-severe pain (visual analog scale $>4$ ) for at least 3 months. Sixty women (54.1 \pm 8.1 years old) diagnosed with fibromyalgia according to the American College of Rheumatology criteria and with moderate-to-severe pain (visual analog scale $>4$ ) also participated in this study. For the dosage of cytokines, blood was collected in the morning: $5 \mathrm{~mL}$ from the cubital vein. The material was centrifuged at $4^{\circ} \mathrm{C}$, separated into $100 \mu \mathrm{L}$ aliquots and stored at $-80^{\circ} \mathrm{C}$ until processing. Serum concentrations of the studied cytokines were assessed using the BD Cytometric Bead Array method. Data were analyzed with Student's $t$-test and the Mann-Whitney $U$ test.

Results: We found higher levels of IL-6, IL-10, and IL-1 $\beta$ in fibromyalgia patients. After adjustment of age as a covariate, there was no statistically significant difference in the concentration of any cytokine between fibromyalgia and knee osteoarthritis patients.

Conclusion: Patients with knee osteoarthritis and fibromyalgia with the same duration and intensity of pain demonstrate similar concentrations of cytokines. Aging may play a role in cytokine profile, a finding not so extensively addressed in the literature and one that should be further investigated.

Keywords: cytokines, osteoarthritis, fibromyalgia, aging

\section{Introduction}

With regard to rheumatic diseases, osteoarthritis (OA) is the most common joint disease in the world, ${ }^{1}$ and symptoms in the knee joint occur in $10 \%$ of women and $13 \%$ of men aged 60 years or older. ${ }^{2,3}$ Another rheumatic disease, fibromyalgia (FM), is characterized by diffused chronic pain that causes many other symptoms, also worth mentioning due to its high annual cost (direct and indirect) of US $\$ 5,945$ per person. ${ }^{4}$ FM negatively impacts quality of life, particularly of women between 45 and 64 years old, ${ }^{5-7}$ which could be aggravated by the aging population, also taking into consideration the fact that this chronic disease has no consensus about its pathogenesis. ${ }^{8}$ Chronic pain is associated with aging and the inflammatory response. ${ }^{9}$ For this reason, we investigated the inflammatory process in two different chronic healthy conditions by assessing serum cytokine levels and profile. Cytokines are a large group of small proteins and polypeptides that are molecules that act on cells involved in immune and inflammatory responses. ${ }^{10}$ Some authors claim that serum levels of certain cytokines may be correlated with such symptoms as pain, depression, and fatigue. ${ }^{11}$ For FM, for example, it is known that loss of balance between proinflammatory and anti-inflammatory serum 
cytokines plays a role in the maintenance of chronic pain, depression, and fatigue. ${ }^{11}$

Although not a specific issue characterizing $\mathrm{FM},{ }^{3}$ there may be a relationship between symptoms and cytokines. ${ }^{8,12-16}$ With regard to $\mathrm{OA}$, these cytokines can also play a major role in the immune response, due to the inflammatory process at the lesion site. ${ }^{17,18} \mathrm{We}$ identified several studies on the levels of serum cytokines IL-6, Il-8, IL-10, IL-1, IL-12p70, and TNF $\alpha$, both on FM and knee OA patients. However, no studies compared both entities using the same data-collection and methodological assessments. Therefore the objective of this study was to compare the concentrations of cytokines in patients with FM and knee OA. We hypothesized that serum levels would be higher in FM patients and that the cytokine profile would be different between both studied groups. Knowledge of the possible role of inflammatory components in both FM and knee OA may improve treatment of these conditions. Therefore, comparing the behavior of cytokines in these two chronic diseases can provide interesting data on the symptomatology and prospects of future treatments.

\section{Materials and methods}

This study was approved by the Ethics Committee for Analysis of Research Projects of Hospital of Clinics, University of São Paulo Medical School, São Paulo, Brazil (CAPPesq 0131/10 and 1176/09). All participants were informed about the study procedure and signed a consent to participate in this study. We recruited women aged 30-65 years with moderate-to-severe pain (visual analog scale $[\mathrm{VAS}] \geq 4)^{19}$ diagnosed with FM according to the American College of Rheumatology. ${ }^{20}$

Excluded from this group were patients diagnosed with psychiatric disease, such as severe depression or schizophrenia, with neurological alterations and/or sequelae, heart disease, coagulopathy, chronic illness, pregnancy, or who had any other rheumatologic disorders, or autoimmune or immunologic diseases. The recruitment of patients/participants was done through referrals from various departments of the University of São Paulo Medical School, through personal contacts, and family members who volunteered to participate.

Knee OA admission criteria included women $\geq 60$ years diagnosed with OA of the knee by the American College of Rheumatology criteria and Kellgren-Lawrence scale grades of 2-4, ${ }^{21,22}$ experiencing moderate-to-severe pain (VAS $\geq 4$ ), ${ }^{19}$ as general averaged level of pain experienced during the day for the past month, lasting $\geq 3$ months. Those who had other rheumatic disease, chronic pain, history of malignancy, previous knee surgery, autoimmune diseases, or active infectious diseases were excluded from the study.

For dosage of the concentrations of serum cytokines, a blood sample $(5 \mathrm{~mL})$ was taken from the cubital vein between 8 am and 11 am and immediately placed in a Vacutainer ${ }^{\circledR}$ (BD, Franklin Lakes, NJ, USA) tube. No addition anticoagulant was added in order to obtain serum after centrifugation at $500 \mathrm{~g}$ and $4^{\circ} \mathrm{C}$. The sera samples were aliquoted in Eppendorf (Hamburg, Germany) Cryotubes and stored at $-80^{\circ} \mathrm{C}$ until use. A human inflammatory cytokines kit (Cytometric Bead Array [CBA]; BD Biosciences, San Jose, CA, USA) was used to quantitatively measure serum concentrations of IL-6, IL-8, TNF $\alpha$, IL-1 $\beta$, IL-10, and IL-12p70 according to the manufacturer's instructions. Individual cytokine concentrations $(\mathrm{pg} / \mathrm{mL})$ were computed using the standard reference curve of CellQuest ${ }^{\mathrm{TM}}$ (BD Biosciences) and CBA software. The reading of the serum samples was performed by the FACSCalibur ${ }^{\mathrm{TM}}$ cytometer (BD Bioscences) of the Laboratory of Medical Investigation - LIM 56, Hospital of Clinics, School of Medicine, University of São Paulo.

\section{Statistical analysis}

The Kolmogorov-Smirnov adjustment test for a normal distribution for all study variables was used. Quantitative characteristics of the patients were described in the two groups with the use of summary measures (mean, standard deviation, median, minimum, and maximum).

Statistical comparisons of the serum levels of IL-6, Il-8, IL-10, IL-1, TNF $\alpha$, and IL-12p70 were made between patients with knee OA and FM. Comparisons between the two groups were made by Student's $t$-test if data were normally distributed, and by Mann-Whitney $U$ test where data were not normally distributed. ${ }^{23}$ We used age as a covariate. Data analysis was done by SPSS 15.0 software (SPSS, Chicago, IL, USA). Statistical significance was set at $P<0.05$, two tailed.

\section{Results}

The study included 53 patients with OA of the knee (71.2 \pm 7.6 years old) and 60 patients with FM (54.1 \pm 8.1 years old). Table 1 shows that patients with OA of the knee were on average statistically older than patients with FM $(P<0.001)$. Other baseline characteristics did not differ statistically between groups $(P>0.05)$. When no statistical adjustment for age was performed, IL-12p70 was significantly higher in patients with OA $(P<0.001)$. Likewise, IL-10 and IL-1 $\beta$ were significantly higher in FM patients $(P=0.001$ and $P<0.001$, respectively). After adjustment for age, there was 
Table I General characteristics of groups: results of Mann-Whitney $U$ test

\begin{tabular}{|c|c|c|c|c|c|c|c|c|}
\hline Variable & Group & Mean & SD & Median & Min & Max & $\mathbf{n}$ & P-value \\
\hline \multirow[t]{2}{*}{ Age (years) } & Knee osteoarthritis & 71.2 & 7.6 & 71.0 & 56.0 & 90.0 & 53 & $<0.001 *$ \\
\hline & Fibromyalgia & 54.1 & 8.1 & 55.0 & 31.0 & 66.0 & 60 & \\
\hline \multirow[t]{2}{*}{ BMI $\left(k g / m^{2}\right)$} & Knee osteoarthritis & 27.9 & 5.9 & 26.9 & 20.0 & 52.7 & 52 & $0.124 *$ \\
\hline & Fibromyalgia & 29.7 & 5.9 & 28.4 & 20.4 & 45.4 & 59 & \\
\hline \multirow[t]{2}{*}{ Duration of pain (months) } & Knee osteoarthritis & 114.6 & 87.0 & 120.0 & 3.00 & 360.0 & 53 & 0.382 \\
\hline & Fibromyalgia & 123.4 & 75.6 & 120.0 & 12.0 & 360.0 & 58 & \\
\hline \multirow[t]{2}{*}{ VAS } & Knee osteoarthritis & 7.4 & 1.9 & 7.8 & 1.8 & 9.9 & 53 & 0.439 \\
\hline & Fibromyalgia & 7.7 & 1.8 & 8.0 & 2.5 & 10.0 & 60 & \\
\hline
\end{tabular}

Note: *Results of Student's t-test.

Abbreviations: SD, standard deviation; Min, minimum; Max, maximum; BMI, body mass index; VAS, visual analog scale.

no difference between the cytokine concentrations between the two groups (Table 2).

\section{Discussion}

Previous studies have shown that in comparison to healthy individuals, OA and FM patients show a significant difference in their concentrations of inflammatory cytokines. ${ }^{12,15,18}$ However, the results of this study indicate that individuals with OA of the knee and FM with similar pain duration and intensity of pain had similar concentrations of cytokines.

Increased levels of proinflammatory cytokines are related to the development and progression of OA due to alteration of gene expression, stimulation of reactive oxygen species production, altered metabolism of articular components, and bone resorption. ${ }^{24-26}$ Some authors have related the loss of functioning to higher levels of serum levels of proinflammatory cytokines. ${ }^{24,27-29} \mathrm{~A}$ study ${ }^{18}$ where muscle biopsy was performed, which verified muscle strength in individuals with knee $\mathrm{OA}$ and a controlled group, found that the first group had lower muscle strength and higher levels of protein/receptor levels of IL-6 compared to healthy subjects; IL-1 was slightly elevated, although not statistically significant, as was IL-8.
Although it is not considered an inflammatory disease, FM can be associated with the presence of inflammatory symptoms with various cytokines, as these are related to the modulation of hyperalgesia, fatigue, sleep disturbances, and pain, among others. The literature suggests that in subjects with FM, there is a lack of regulation of cytokines IL-1, IL-6, and IL-8. ${ }^{13,30}$ When comparing a control group and patients with FM, Wallace et al ${ }^{12}$ found that the latter had higher serum levels of IL-8 compared to the controls, and the authors also added that IL- 6 may be responsible for many symptoms of FM, such as hyperalgesia, fatigue, and depression. Other authors ${ }^{14}$ also observed an increase in IL serum levels of IL-10, IL-8 and TNF $\alpha$ in patients with FM compared with control subjects. Another study suggests that the serum level of IL-8 in patients with FM contributes to increased pain intensity. ${ }^{15}$

To our knowledge, there are no studies comparing cytokines in patients with rheumatic diseases, specifically between FM and OA, the two major rheumatic diseases. Therefore, it is difficult to compare data from our study. Our study presented three factors - body composition, duration, and intensity of pain - that could have interfered with the results,

Table 2 Comparison of results of serum cytokine concentration between fibromyalgia and knee osteoarthritis patients

\begin{tabular}{|c|c|c|c|c|c|c|c|c|c|}
\hline Variable & Group & Mean & SD & Median & Min & $\operatorname{Max}$ & $\mathbf{n}$ & $P$-value* & P-value ${ }^{\#}$ \\
\hline \multirow[t]{2}{*}{ IL-I2p70 (pg/mL) } & Knee osteoarthritis & 11.4 & 37.36 & 0.0 & 0.0 & 178.3 & 53 & $<0.001$ & 0.156 \\
\hline & Fibromyalgia & 7.7 & 26.17 & 2.6 & 0.0 & $17 \mid .5$ & 60 & & \\
\hline \multirow{2}{*}{$\mathrm{TNF} \alpha(\mathrm{pg} / \mathrm{mL})$} & Knee osteoarthritis & 2.2 & 4.52 & 1.2 & 0.0 & 24.2 & 53 & 0.128 & 0.630 \\
\hline & Fibromyalgia & 2.0 & 2.08 & 2.0 & 0.0 & I I.7 & 60 & & \\
\hline \multirow[t]{2}{*}{ IL-IO (pg/mL) } & Knee osteoarthritis & 1.6 & 2.36 & 1.2 & 0.0 & 15.7 & 53 & 0.001 & 0.949 \\
\hline & Fibromyalgia & 2.0 & 1.13 & 2.0 & 0.0 & 7.8 & 60 & & \\
\hline \multirow[t]{2}{*}{ IL-6 (pg/mL) } & Knee osteoarthritis & 4.4 & 4.61 & 2.8 & 1.2 & 19.3 & 53 & 0.488 & 0.395 \\
\hline & Fibromyalgia & 3.5 & 1.86 & 3.3 & 0.0 & 12.3 & 60 & & \\
\hline \multirow[t]{2}{*}{$\mathrm{IL}-\mathrm{I} \beta(\mathrm{pg} / \mathrm{mL})$} & Knee osteoarthritis & 1.9 & 3.30 & I.I & 0.0 & 17.0 & 53 & $<0.001$ & 0.143 \\
\hline & Fibromyalgia & 3.4 & 2.27 & 2.7 & 0.0 & 14.0 & 60 & & \\
\hline \multirow[t]{2}{*}{ IL-8 (pg/mL) } & Knee osteoarthritis & 10.6 & 8.50 & 8.7 & 0.0 & 53.5 & 53 & 0.434 & 0.688 \\
\hline & Fibromyalgia & 10.5 & 8.67 & 7.2 & 0.0 & 45.5 & 60 & & \\
\hline
\end{tabular}

Notes: *Results of Mann-Whitney $U$ test; ${ }^{*}$ results of test adjusted for age.

Abbreviations: SD, standard deviation; Min, minimum; Max, maximum; IL, interleukin; TNF, tumor necrosis factor. 
but as these were similar between groups, it is believed that the results related to the concentration of cytokines were due to the condition of the disease itself.

When results without adjusting for age were checked, the OA group showed a higher concentration of proinflammatory IL-12p70 cytokines in relation to the FM group. The FM group had higher concentrations of one proinflammatory (IL-1) and one immunomodulatory cytokine (IL-10) compared to the OA group. However, these differences did not remain when adjustment for age was done.

Aging may influence cytokine profile, and should always be taken into consideration. Noncommunicable chronic conditions/diseases and the aging process are global conditions that currently have a an increased prevalence. Both conditions are now a public health priority. Better understanding of the influence and impact of aging in the pathophysiology of common health conditions is urgently needed. ${ }^{31}$ Studies have indicated that patients with FM present shortened telomere length, a measure of biological age, when compared to a control group of individuals, also indicating that when pain and depression are associated with this type of patient and there might be a consistent difference of approximately 6 years in chronological aging. ${ }^{9}$ Therefore, it is believed that these chronic diseases, often present in middle-aged and elderly women with FM and also elderly individuals with OA, can accelerate the process of aging.

Another factor that should be considered is that besides the pathogenesis of these chronic diseases (FM and OA) being dependent on the combination of genetic, psychological, and environmental factors, ${ }^{32}$ there is also the factor of hypersensitivity within the diffuse neural networks of the central nervous system involved in nociception. This explains the fact that the treatment for this type of disease should not be focused only on reducing pain but also on the improvement of abnormalities in peripheral sensitization/ neuroendocrine abnormalities and the central/autonomic nervous system. ${ }^{33}$ As stated by Staud, ${ }^{33}$ educational programs, exercise, and cognitive therapies should also be associated with treatment.

Ortega et $\mathrm{al}^{34}$ describe an indirect way of controlling cytokines by the practice of regular exercise. Physical exercise in patients with rheumatic diseases should aim to improve local symptoms and overall health. ${ }^{35}$ Exercise is important, since disuse and the aging process are associated with increased inflammation. ${ }^{18}$

Ortega et $\mathrm{al}^{34}$ reported that after an exercise program carried out in an indoor swimming pool, FM volunteers showed a significant decrease in serum levels of IL-8, inteferon and C-reactive protein with decreased concentration of circulating cortisol and noradrenaline levels. ${ }^{15}$ Wang et al ${ }^{15}$ reported that after 6 months of multidisciplinary therapy against pain, there was decreased serum concentration of IL-8 in women with FM. Another important issue is the increase in markers of muscle inflammation often present in both FM and OA related with reduced muscle strength, ${ }^{18}$ and exercise can cause an increase in the concentration of intraarticular and perisynovial fluid of protein/receptor levels of IL-10 in women, suggesting that exercise beneficially acts on chondroprotective anti-inflammatory cytokines in patients with OA. ${ }^{36}$ As for IL-1 $\beta$ concentration, which is among the most important mediators involved with inflammatory response, ${ }^{37}$ a higher concentration was observed within patients with FM (when age was not adjusted). However, it is believed that this type of cytokine is also important in patients with OA, because its expression is also associated with the loss of muscle mass due to aging, ${ }^{38}$ a very common event in patients with OA. It is important to recommend patients with these chronic diseases for physical exercise, because of loss of muscle mass, and also because exercise can positively affect muscle $\mathrm{pH}$ and blood flow. ${ }^{39}$

We must not forget about ideal body weight in patients with chronic diseases, since adipose tissue increases the synthesis of pro-inflammatory cytokines, such as IL-6, IL-1, IL-8, TNF $\alpha$, and IL-18, and decreases the regulatory cytokines, such as IL-10. ${ }^{40}$ In the present study, although the two groups were similar with respect to this factor, both showed high values of body composition in relation to patterns of normality. ${ }^{41}$

Our study had some limitations. First, we did not measure all existing cytokines, eg, IL-17 or IL-18. Before starting the study, we performed an extensive literature search on existing information regarding serum levels of cytokines in patients diagnosed with knee OA. We decided to analyze the cytokines in our study that could be compared with previously published papers. Further studies should explore the role of other cytokines in these patients. Second, we did not include a control group of healthy volunteers, due to budgetary restrictions. Finally, age was significantly different between the two groups. We therefore adjusted the statistical analyses using age as a covariate. In fact, our results demonstrate higher levels of IL-6, IL-10, and IL-1 $\beta$ in FM patients. However, when adjusted for age, these differences were no longer present. This indicates that aging may play a role in the cytokine profile, a finding not so extensively addressed in the literature and one that should be further investigated. 
Future study should focus on the detection of cytokines in the skin, which could indicate the presence of the focus of inflammation that may occur in about $30 \%$ of patients of $\mathrm{FM}^{42}$ We believe that the investigation of pressure pain threshold on points that present less tolerance to pressure in patients with OA and FM could lead to interesting results.

We conclude that patients with OA and FM with the same duration and intensity of pain have similar values for the concentration of cytokines, showing that there is no difference in the level of cytokine concentrations between these two chronic rheumatic diseases that affect middle-aged and elderly people.

\section{Disclosure}

The authors report no conflicts of interest in this work.

\section{References}

1. Alkan BM, Fidan F, Tosun A, Ardıçoğlu O. Quality of life and selfreported disability in patients with knee osteoarthritis. Mod Rheumatol. 2014;24(1):166-171.

2. Kotlarz H, Gunnarsson CL, Fang H, Rizzo JA. Insurer and out-of-pocket costs of osteoarthritis in the US: evidence from national survey data Arthritis Rheum. 2009;60(12):3546-3553.

3. Ang DC, Moore MN, Hilligoss J, Tabbey R. MCP-1 and IL-8 as pain biomarkers in fibromyalgia: a pilot study. Pain Med. 2011;12(8):1154-1161.

4. Centers for Disease Control and Prevention. Fibromyalgia. 2012. Available from: http://www.cdc.gov/arthritis/basics/fibromyalgia.htm. Accessed December 6, 2013.

5. Forseth KO, Gran JT. The prevalence of fibromyalgia among women aged 20-49 years in Arendal, Norway. Scand J Rheumatol. 1992; 21(2): 74-78.

6. Pongratz DE, Sievers M. Fibromyalgia - symptom or diagnosis: a definition of the position. Scand J Rheumatol Suppl. 2000;113:3-7.

7. Russel IJ. Fibromalgia syndrome. In: Loeser JD, Butler SH, Chapman CR, Turkey DC, editors. Bonica's Management of Pain. 3rd ed. Philadeplphia: Lippincott Williams \& Wilkins; 2001:543-556.

8. Menzies V, Lyon DE. Integrated review of the association of cytokines with fibromyalgia and fibromyalgia core symptoms. Biol Res Nurs. 2010;11(4):387-394.

9. Hassett AL, Epel E, Clauw DJ, et al. Pain is associated with short leukocyte telomere length in women with fibromyalgia. J Pain. 2012 13(10):959-969.

10. Curfs J, Meis J, Hoogkamp-Korstanje J. A primer on cytokines: sources, receptors, effects, and inducers. Clin Microbiol Rev. 1997;10(4): 742-780.

11. Uçeyler N, Häuser W, Sommer C. Systematic review with metaanalysis: cytokines in fibromyalgia syndrome. BMC Musculoskelet Disord. 2011;12:245.

12. Wallace DJ, Linker-Israeli M, Hallegua D, Silverman S, Silver D, Weisman MH. Cytokines play an aetiopathogenetic role in fibromyalgia: a hypothesis and pilot study. Rheumatology (Oxford). 2001;40(7): 743-749.

13. Gür A, Karakoç M, Nas K, et al. Cytokines and depression in cases with fibromyalgia. J Rheumatol. 2002;29(2):358-361.

14. Bazzichi L, Rossi A, Massimetti G, et al. Cytokine patterns in fibromyalgia and their correlation with clinical manifestations. Clin Exp Rheumatol. 2007;25(2):225-230.

15. Wang H, Buchner M, Moser MT, Daniel V, Schiltenwolf M. The role of IL-8 in patients with fibromyalgia: a prospective longitudinal study of 6 months. Clin J Pain. 2009;25(1):1-4.

16. Togo F, Natelson BH, Adler GK, et al. Plasma cytokine fluctuations over time in healthy controls and patients with fibromyalgia. Exp Biol Med. 2009;234(2):232-240.
17. Livshits G, Zhai G, Hart DJ, et al. Interleukin-6 is a significant predictor of radiographic knee osteoarthritis: the Chingford Study. Arthritis Rheum. 2009;60(7):2037-2045.

18. Levinger I, Levinger P, Trenerry MK, et al. Increased inflammatory cytokine expression in the vastus lateralis of patients with knee osteoarthritis. Arthritis Rheum. 2011;63(5):1343-1348.

19. Chapman RS, Syrjala KL. Measurement of pain. In: Bonica JJ, editor. The Management of Pain. 2nd ed. London: Lea \& Febiger; 1990:580-594.

20. Wolfe F, Smythe HA, Yunus MB, et al. The American College of Rheumatology 1990 criteria for the classification of fibromyalgia. Report of the Multicenter Criteria Committee. Arthritis Rheum. 1990;33(2): $160-172$.

21. Altman R, Asch E, Bloch D, et al. Development of criteria for the classification and reporting of osteoarthritis. Classification of osteoarthritis of the knee. Diagnostic and Therapeutic Criteria Committee of the American Rheumatism Association. Arthritis Rheum. 1986;29(8): 1039-1049.

22. Ravaud P, Auleley GR, Chastang C, et al. Knee joint space width measurement: an experimental study of the influence of radiographic procedure and joint positioning. Br J Rheumatol. 1996;35(8): 761-766.

23. Kirkwood BR, Sterne JAC. Essential Medical Statistics. 2nd ed. Massachusetts: Blackwell Science; 2006.

24. Miller GD, Nicklas BJ, Loeser RF. Inflammatory biomarkers and physical function in older, obese adults with knee pain and self-reported osteoarthritis after intensive weight-loss therapy. $J$ Am Geriatr Soc. 2008;56(4):644-651.

25. Pelletier JP, Martel-Pelletier J, Abramson SB. Osteoarthritis, an inflammatory disease: potential implication for the selection of new therapeutic targets. Arthritis Rheum. 2001;44(6):1237-1247.

26. Saxne T, Lindell M, Månsson B, Petersson IF, Heinegård D. Inflammation is a feature of the disease process in early knee joint osteoarthritis. Rheumatology. 2003;42(7):903-904.

27. Ferrucci L, Penninx BW, Volpato S, et al. Change in muscle strength explains accelerated decline of physical function in older women with high interleukin-6 serum levels. J Am Geriatr Soc. 2002;50(12): 1947-1954.

28. Penninx BW, Abbas H, Ambrosius W, et al. Inflammatory markers and physical function among older adults with knee osteoarthritis. J Rheumatol. 2004;31(10):2027-2031.

29. Ferraro KF, Booth TL. Age, body mass index, and functional illness. J Gerontol B Psychol Sci Soc Sci. 1999;54(6):S339-S348.

30. Wallace DJ. Is there a role for cytokine based therapies in fibromyalgia. Curr Pharm Des. 2006;12(1):17-22.

31. Mobily PR, Herr KA, Clark MK, Wallace RB. An epidemiologic analysis of pain in the elderly: the Iowa $65+$ health study. J Aging Health. 1994;6(2):139-154.

32. Diatchenko L, Nackley AG, Slade GD, Fillingim RB, Maixner W. Idiopathic pain disorders - pathways of vulnerability. Pain. 2006; 123(3):226-230

33. Staud R. Treatment of fibromyalgia and its symptoms. Expert Opin Pharmacother. 2007;8(11):1629-1642.

34. Ortega E, García JJ, Bote ME, et al. Exercise in fibromyalgia and related inflammatory disorders: known effects and unknown chances. Exerc Immunol Rev. 2009; 15:42-65.

35. Maddali Bongi S, Del Rosso A. [How to prescribe physical exercise in rheumatology]. Reumatismo. 2010;62(1):4-11. Italian.

36. Helmark IC, Mikkelsen UR, Børglum J, et al. Exercise increases interleukin-10 levels both intraarticularly and peri-synovially in patients with knee osteoarthritis: a randomized controlled trial. Arthritis Res Ther. 2010;12(4):R126.

37. Ferrero-Miliani L, Nielsen OH, Andersen OS, Girardin SE. Chronic inflammation: importance of NOD2 and NALP3 in interleukin-1 $\beta$ generation. Clin Exp Immunol. 2006;147(2):227-235.

38. Peake J, Della Gatta P, Cameron-Smith D. Aging and its effects on inflammation in skeletal muscle at rest and following exerciseinduced muscle injury. Am J Physiol Regul Integr Comp Physiol. 2010;298(6):R1485-R1495. 
39. Staud R. Peripheral pain mechanisms in chronic widespread pain. Best Pract Res Clin Rheumatol. 2011;25(2):155-164.

40. Iannone F, Lapadula G. Obesity and inflammation - targets for OA therapy. Curr Drug Targets. 2010;11(5):586-598.

41. World Health Organization. Physical Status: The Use and Interpretation of Anthropometry. Geneva: WHO; 1995.
42. Salemi S, Rethage J, Wollina U, et al. Detection of interleukin 1beta (IL-1beta), IL-6, and tumor necrosis factor-alpha in skin of patients with fibromyalgia. J Rheumatol. 2003;30(1):146-150.

\section{Publish your work in this journal}

Clinical Interventions in Aging is an international, peer-reviewed journal focusing on evidence-based reports on the value or lack thereof of treatments intended to prevent or delay the onset of maladaptive correlates of aging in human beings. This journal is indexed on PubMed Central, MedLine,
CAS, Scopus and the Elsevier Bibliographic databases. The manuscript management system is completely online and includes a very quick and fair peer-review system, which is all easy to use. Visit http://www.dovepress. com/testimonials.php to read real quotes from published authors. 